\title{
LAS AMANTES DE FRANCISCO UMBRAL
}

\section{THE LOVERS OF FRANCISCO UMBRAL}

Fabienne Uni

Université de Pau et des pays de L'Adour

\section{ABSTRACT}

Besides the provocative aspect of his novels, Francisco Umbral's personal life has always given people plenty to talk about since he boasted about many a mistress. One of them, the poetess Blanca Andreu, became the female main character in some of his well-known novels of the Spanish Transition: Los amores diurnos, La bestia rosa, Los ángeles custodios and $A$ la sombra de las muchachas rojas. However, the autobiographic novel of Vicente Molina-Foix and Luis Cremades, El invitado amargo (2014), read in the light of endless details within the very texts of the aforesaid novels, enabled me to discover another female lover who, although discreet was nonetheless worthy of interest.

Keywords: Francisco Umbral, Vicente Molina-Foix, autobiography, erotism.

\section{RESUMEN}

Además del aspecto provocativo de sus obras, la vida personal de Francisco Umbral siempre dio que hablar por fanfarronear de amantes. Una de ellas, la poeta Blanca Andreu, pasó a ser 
protagonistas de unas de sus novelas más sonadas de la Transición: Los amores diurnos, La bestia rosa, Los ángeles custodios y $A$ la sombra de las muchachas rojas. Sin embargo, la novela autobiográfica de Vicente Molina-Foix y Luis Cremades, El invitado amargo (2014), contrastada con un sinfín de detalles sacados de dichas obras me ha permitido descubrir a otra amante aunque, por discreta, no menos relevante.

Palabras clave: Francisco Umbral, Vicente Molina-Foix, autobiografía, erotismo.

Fecha de recepción: 11 de octubre de 2021.

Fecha de aceptación: 4 de noviembre de 2021.

Cómo citar: Uni, Fabienne (2021): «Las amantes de Francisco Umbral», en Actio Nova: Revista de Teoría de la Literatura y Literatura Comparada, 5: 162-182.

DOI: https://doi.org/10.15366/actionova2021.5.008 
«Más que culpable de amores y amoríos, por ejemplo, soy culpable, a estas alturas, de leyenda y sospecha ${ }^{1}$, y eso has aprendido a llevarlo tú, entre la indiferencia y la maternidad, como diciendo a los demás: "Dejadle que viva su vida, que juegue a sus juegos: es un niño"» (Umbral, 2008: 152). Con estas palabras dedicadas a su mujer María España, Francisco Umbral pretende desmentir el aura de gran mujeriego que le va persiguiendo. De tal modo que, al poner en duda su fama de Tenorio, queda destacada la creación de su «persona» literaria -en el sentido jungiano del término, o sea la máscara social que cada uno tenemos que usar para adaptarnos a las exigencias de la sociedad- más que un supuesto libertinaje que expuso ampliamente para provocar y dar que hablar. De paso, demuestra que el escritor es un gran mentiroso puesto que ya menciona sus «amores y amoríos», algunos muy sonados, en una de las conversaciones que mantiene con Eduardo Martínez Rico en torno a su libro Madrid, tribu urbana (Martínez Rico, 2001)2.

Tal y como su mujer, María España, lo reconoció, nunca se puso violenta, excepto una vez, con «una joven de provincias» al padre de quien tuvo que llamar para deshacerse de ella (Villena, 2019: 2). «Ha sido la única vez que me he mostrado violenta. ¡La única!» (Plaza, José María; Darriba, Manuel; Caballero, Javier, 2007), comentó la esposa indulgente. La «poeta» mencionada en este artículo era por supuesto la conocida Blanca Andreu, quien mantuvo una relación con el escritor entre 1978 y 1980, y que pasará a ser Rimbaud en La bestia rosa, novela publicada en 1981 en la colección de La sonrisa vertical, de Luis G. Berlanga.

Un affaire de notoriedad pública que Anna Caballé, en su biografía no autorizada de Umbral, El frío de una vida, remarca:

Como todo el mundo sabe, bajo el nombre de Rimbaud, Umbral quiso que se encubriera a una joven poeta con la que el escritor mantuvo entre 1978 y 1980 la relación extraconyugal más seria e importante de cuantas ha vivido. [...] En 1978 Umbral tiene cuarenta y seis años. La joven poeta... veinte. La relación fue un fogonazo que prendió rápido en el corazón de ambos. Ella abandonaría muy pronto sus estudios de filología en la Universidad Complutense para acompañar al escritor en sus desplazamientos fuera de Madrid (Caballé, 2004: 341-342).

\footnotetext{
${ }^{1}$ El subrayado es mío.

2-El libro que vas a publicar próximamente, Madrid, tribu urbana, son unas memorias políticas, ¿verdad? -Bueno, políticas, pero hay de todo. Hay vida social, hay amores y amoríos, hay de todo, hay literatura. Hay de todo. (Martínez Rico, 2001).
} 
Una relación que también recuerda Luis Antonio de Villena. Así, en el tercer volumen de sus memorias, Las caídas de Alejandría, recientemente publicado, dice:

Una de las primeras poetas jóvenes a las que conocí (y enseguida traté), supongo que en 1981, fue Blanca Andreu -poeta, pues ya no se quería decir poetisa-. Blanca (entonces amante casi oficia 3 de Paco Umbral, se dejaban ver por las tardes) había tenido notable éxito [...] con su primer libro de poemas (Villena, 2019: 292).

Luego añade: «Los vi bastantes veces juntos. Y también se dice (Blanca lo negaba, pero eso suele ser muy normal) que Umbral escribió, tras el fin, una novela erótica que narra -con ficción, desde luego- su historia: La bestia rosas. A pesar de su negativa, como lo confirma Francisco Umbral a Eduardo Martínez Rico en una entrevista de 2003, sí que es Blanca Andreu la Rimbaud de La bestia rosa: «-La protagonista de La bestia rosa es Blanca Andreu. Blanca Andreu era una ninfa, una ninfa efébica maravillosa» (Martínez Rico, 2003: $28)^{4}$. Tan maravillosa que pudo tambalear la vida de un matrimonio ya asentado ${ }^{5}$ cuando «Rimbaud, digo, me pidió que me quedase a pasar la vida con ella» (Umbral, 1981b: 51).

El mundo de «las ninfas» umbralianas lo enfoca y detalla minuciosamente Ignacio Díez Fernández en 2010 en un artículo, «Trío de jóvenes y andróginas», en el cual estudia, entre otros, las figuras andróginas de las protagonistas de La bestia rosa y de $A$ la sombra de las muchachas rojas (Crónicas marcianas de la transición), ambas obras publicadas en 1981. Sostiene que «De todas ellas, la más conocida será, sin duda, la joven que completa necesariamente la figura que da título a La bestia rosa» (Díez, 2010: 127) y compara sus similitudes y diferencias. A lo cual me parece que se puede añadir la figura femenina de Mozart de Los ángeles custodios, -obra también publicada en el 81- dado que la andrógina de esta obra se oculta tras la máscara de «Mozart» al igual que la de $A$ la sombra de las muchachas rojas. Umbral, después de haber declarado que iba a escribir un libro entero sobre «la niña» (Umbral, 1981a: 115), no honra su palabra y tiende a hablar de otras cosas.

Como lo demuestra Díez Fernández, las protagonistas de La bestia rosa y de $A$ la sombra de las muchachas rojas, Mozart y Rimbaud, «esconden a una misma mujer» (Díez, 2010: 131). De hecho, en $A$ la sombra de las muchachas rojas Francisco Umbral utiliza los dos nombres,

\footnotetext{
${ }^{3}$ El subrayado es mío.

${ }^{4}$ También Villena corrobora las palabras de la viuda de Francisco Umbral, cuando afirma: «Según María España [...] Blanca estuvo locamente enamorada de su marido, y hasta le aguardaba en el portal de la casa, cosa que España - me contó- prohibió con cajas destempladas, ayudada por el portero» (Villena, 2019: 294).

${ }^{5}$ Francisco Umbral y María España Suárez Garrido se habían casado en Valladolid el 8 de septiembre de 1959.
} 
Mozart y Rimbaud, para señalar a la misma chica, aunque mucho más el primero (treinta y ocho ocurrencias) que el segundo (cinco ocurrencias). A la lista de similitudes establecida por Díez Fernández entre Mozart y Rimbaud ${ }^{6}$ habría que añadir la falta de senos de Mozart en las primeras páginas de Los ángeles custodios, así como su androginia: «Lo que pasa con Mozart es que no tiene senos. Es una muchacha sin senos. Su pecho es como el pecho de un hombre que fuese una mujer, de un adolescente que fuese una adolescente» (Umbral, 1981a: 19). El autor/amante comenta que «la niña» fuma marihuana e incluso consume «cocaína» (Umbral, 1981a: 210-211, 232). La asocia frecuentemente con Marc Chagall ${ }^{7}$. Mentar a este pintor también llamó la atención de Ignacio Díez quien la considera una «maliciosa e inequívoca pista» (Díez, 2010: 132). Es cierto que Chagall remite directamente a Blanca Andreu como lo demuestra la descripción que hace Umbral de «Mozart» y «Rimbaud». Nacida en 1959, la sílfide estudiante de filología llega a Madrid en $1978^{8}$ para terminar su carrera universitaria. Gana el Premio Adonáis con un poemario titulado De una niña de provincias que se vino a vivir en un Chagall, un título que muchos consideraron «algo umbraliano» (Villena, 2019: 292; Caballé, 2004: 342). Ambas jóvenes son bisexuales. La Rimbaud de La bestia rosa afirma que es «bisex», y su amante, aunque «el posible safismo de la niña» le excita, teme que le abandone para irse con una mujer:

Lo que más me gusta de todo es que Rimbaud sea lesbiana en potencia, lesbiana platónica (qué jaleo griego más raro). «Soy bisexual», me corrige. Pero se masturba soñando con niñas de caramelo y le fascinan los grandes senos de las grandes mujeres, porque ella no tiene. A Rimbaud no me la llevará un hombre, sino, en todo caso, una bella mujer (Umbral, 1981b: 32, 113, 87)9.

Si es cierto que la Mozart de Los ángeles custodios no hace semejante declaración, Umbral evoca su supuesto safismo:

\footnotetext{
${ }^{6}$ En la comparación de ambas, Mozart y Rimbaud, hay que anotar otros muchos puntos en común: son universitarias, disponen de un finísimo recto, tienen cabeza de «Salzillo, consumen «has», son las «niñas», tienen un coño muy específico (en Mozart, «su barroco coño alegrando la mañana como un clavel, entre la selva negra y abundante de su pubis»), son adictas al nesquik, se consideran viejas (Mozart porque pasa de los quince), etc. Por si no bastara, se desliza esta maliciosa e inequívoca pista: «Mozart estaba en su Chagall» (Díez, 2010: 132). ${ }^{7}$ Como por ejemplo en «Mozart ha venido de un mar cargado de fruta y unas noches encendidas de cocaína a instalarse en un Chagall madrileño, a vivir de inquilina en el interior de un póster de Chagall» (Umbral, 1981a: $211,210,232,240,245)$.

${ }^{8}$ Según afirma Anna Caballé, al contrario de las biografías de Blanca Andreu encontradas en internet que mencionan que se trasladó a Madrid en 1979. Véase, por ejemplo: «A los 20 años, dejó Oribuela (Alicante), donde residía para dirigirse a Madrid, donde inició su carrera literaria». Anon (2021): «Poetas del alma»: en https://www.poemas-del-alma.com/blanca-andreu.htm\#block-bio (último acceso: 23/08/2021).

${ }_{9}$ Véanse también (Umbral, 1981b: 113, 87).
} 
Mozart ha venido con una amiga que se queda a vivir con ella, de momento. La amiga es provinciana, viciosa, también muy joven, drogota, con las ojeras abultadas bajo la mirada de niña que se ha emborrachado de mistela. (Sospecho que de coca.) Ambas se han instalado en el azul/Chagall y viven enredadas en un apretado caos de droga, material, safismo, sofisma o lo que sea. No me siento con ganas ni necesidad de desenredar el lío. El cansancio le hace a uno infinitamente liberal (Umbral, 1981a: 240).

Todos estos hechos concuerdan con la hipótesis que la joven poeta es el mismo modelo para los personajes de Mozart y Rimbaud en La bestia rosa y Los ángeles custodios. Aunque siempre he dado por seguro que Blanca Andreu era «la» amante oficial y más conocida del autor, su musa (y que era, sino la protagonista, por lo menos la inspiración de estas figuras femeninas de los libros que el autor había escrito a finales de los 70 o principios de los 80, en plena Transición), varias lecturas detenidas me han llevado a reconsiderar este hecho: Los ángeles custodios (1981), La bestia rosa (1981) así como Los amores diurnos (1979).

Los ángeles custodios tiene forma de un diario íntimo, pero es un diario de reflexiones sobre la noche madrileña, los famosos con quienes Umbral se relaciona, la literatura, el sexo, etc. Según las propias palabras del autor es un diario «cuya crónica nocturna -ay- cuyo noctuario íntimo o público llenará en gran parte este libro. De entre las muchachas, una» (Umbral, 1981a: 14). Las entradas empiezan la noche del 21 al 22 de marzo, o sea durante el equinoccio de «primavera» stricto sensu, y termina en la noche del 15 al 16 de diciembre. Resulta difícil dar con las fechas exactas ya que las entradas no precisan el día específico, aunque no faltan los indicios ${ }^{10}$.

La bestia rosa, la segunda novela en términos cronológicos (la novela anterior fue publicada en junio de 1981 y esa en diciembre del mismo año), también tiene forma de diario íntimo. Las entradas se extienden desde el domingo 21 de diciembre (1980) hasta el martes 23 de junio - esta vez entre dos equinoccios (seguramente del año 1981, ya que las fechas día/número corresponden, aunque Umbral no lo precisa). Asimismo, se puede considerar que La bestia rosa es la continuación de Los ángeles custodios y, en un plazo tan corto de publicación, lógicamente uno piensa que la protagonista sigue siendo la misma. Es un diario erótico, el número veintiocho de la colección de La sonrisa vertical del erotómano Berlanga.

\footnotetext{
${ }^{10}$ En efecto, la entrada de la noche del 25 al 26 del mes de abril viene con una indicación que se puede comprobar fácilmente: «Cena en el Ritz. Me entregan el premio González-Ruano» (Umbral, 1981a: 39).

$\mathrm{Al}$ escritor le entregaron este premio por su artículo, «El trienio» (artículo publicado el 10 de enero de 1979 en El País) en 1980. Fundación Francisco Umbral (2021): «Se le otorga el Premio César González-Ruano, uno de los más prestigiosos en el mundo periodístico, por el artículo "El Trienio" publicado en el diario El País», en https://www.fundacionfranciscoumbral.es/escritor/biografia.php (último acceso: 26/07/2021).
} 
Umbral lo considera un «diario de amor» (Umbral, 1981b: 106), su «libro más sexual o erótico», el que presenta una mayor «intimidad sexual con una mujer» (Martínez Rico, 2001: $181)^{11}$.

Los amores diurnos se publica en marzo de 1979, cuando Francisco Umbral mantiene una relación con Blanca Andreu. No es un diario, sino una «memoria erótica y profundamente poética - de tintes surrealistas-sobre su relación con la joven Leticia/Lutecia (nombre literario de una tal M.)», según la presenta Antonio Tausiet en su blog sobre $\mathrm{Umbral}^{12}$. ¿«M» por «Mozart»? La cuarta de cubierta la presenta como un «poema-ensayonovela-diario», una «metáfora de sexo» mientras que Eduardo Martínez Rico la clasifica entre los «libros eróticos» del autor (Martínez Rico, 2002: 69) ${ }^{13}$.

Hasta entonces se considera que la Leticia/Lutecia de Los amores diurnos es la famosa poeta. Es cierto que existen pequeños detalles, indicios que demuestran que las chicas de ambas novelas son dos mujeres distintas, pero únicamente una lectura muy detenida permite desvelarlo; a veces incluso de manera retroactiva.

Umbral no da muchos detalles físicos de ambas jóvenes, pero una vez que se ha comprobado que la musa de Umbral para el personaje de Rimbaud/Mozart es Blanca Andreu, es evidente que la «niña» de Los amores diurnos no es el mismo modelo. Cuando se comparan las descripciones de ambas Rimbaud/Mozart con la Leticia/Lutecia de Los amores diurnos, no se puede evitar encontrar similitudes: su juventud -55 ocurrencias de «la niña»su aspecto andrógino -«la efébica niña» (Umbral, 1979b: 36) - además de varias alusiones al Orlando de Virginia Woolf y su consumo de droga: «Leticia/Lutecia tiene unas alas purísimas de cocaína, una cocaína del tamaño de lo blanco, unas alas del plumaje del sueño» (Umbral, 1979b: 141). Ahora bien, tanto la juventud como el carácter andrógino indican claramente los puntos de atracción para Umbral. En cuanto al consumo de droga, cristaliza el ambiente de la época.

Pese a ello, destacan igualmente unas diferencias significativas. En concreto en el texto de Los amores diurnos, no se menciona safismo alguno de «la niña». Al contrario, el narrador se deja llevar por los celos al verla con otros hombres: «Y así es como he visto, veo, veré a Leticia/Lutecia internándose en el bosque masculino de hombres cada vez mayores»

${ }^{11}$ Citado por (Blanco, 2012: «Un jardín de coños»: notas sobre la materia erótica en Francisco Umbral», Analecta Malacitana, $\mathrm{n}^{\circ}$ 32: 571-603).

12 Tausiet, Antonio (2015): «Francisco Umbral. Todas sus obras ordenadas», en http://seronoser.free.fr/umbral/(último acceso: 02/07/2021).

13 «Atendiendo a rasgos más concretos de cada obra, se puede hablar también de libros eróticos (como La bestia rosa, Historias de amor y viagra, Los amores diurnos)». 
(Umbral, 1979b: 112). Es más, por primera vez, el autor menciona una docena de veces en el libro que la niña es «asmática». Véase por ejemplo «El asma de L/L haría de ella un Proust enajenado» (Umbral, 1979b: 75).

Cierto es que ambas, Rimbaud/Mozart y Leticia/Lutecia, consumen drogas, pero Umbral insiste mucho más en el consumo de cocaína de Leticia/Lutecia. No mienta marihuana ni has. De hecho, «las alas de cocaína» sobre las cuales vuela la protagonista de Los amores diumos aparecen repetidas en el texto (Umbral, 1979b: 141-142, 145, 148$149,162,177,213)$.

Asimismo, Blanca Andreu tiene el pelo moreno; esto se puede verificar en las fotos y en algunas indirectas del texto de La bestia rosa: «sé que te gustan las rubias, yo soy morena, sí, y qué, vete a la mierda» (Umbral, 1981b: 31) ${ }^{14}$, cuando en el texto del libro publicado dos años antes insiste en lo «rubia» $\mathrm{O}$ «dorada» que es Leticia/Lutecia ${ }^{15}$.

A estas distinciones textuales se sumaron otros indicios, los de María España, la viuda del famoso escritor, quien recordó que su matrimonio fue sometido a duras pruebas en dos ocasiones:

También hubo otra joven vecina, hija de un pintor $^{16}$, que puso en peligro su matrimonio. «Esas han sido las dos mujeres, de tantas que hubo a su alrededor, que llegaron demasiado lejos. Las demás..., iqué más da! Yo no soy orgullosa y comprendo que un escritor debe vivir muchas cosas y yo no podía limitarle» (Plaza, José María; Darriba, Manuel; Caballero, Javier, 2007).

Y de nuevo surge une «M» en la conversación que Anna Caballé tuvo con Blanca Andreu:

Decido llamar a Rimbaud para preguntarle su opinión sobre 'La bestia rosa'. Lo hago el 30 de marzo de 2001, sobre la una de la tarde. Mantenemos una conversación muy tensa, hasta el extremo de amenazarme ella con los tribunales si me atrevo a vincularla con el escritor. [...] Sin dejar su voz arrogante, Rimbaud comenta su costumbre de utilizar las relaciones sentimentales que ha mantenido para escribir sus libros, cargados de referencias a mujeres reales. Me habla de $\mathrm{M}$, que le inspiró un libro anterior, 'Los amores diurnos', y con la que desde luego pensaba ponerme en contacto. 'A ver si tiene usted huevos para hablar con ella y preguntarle por él' (Caballé, 2004: 343).

\footnotetext{
${ }^{14}$ Hay dos otras alusiones al pelo moreno de la «niña» (Umbral, 1981b: 35, 74).

15 Trece ocurrencias de la palabra "rubia" contabilizadas (Umbral, 1979b: 18-215), nueve de "rubio" (Umbral, 1979b: 60-221) y dos de "dorada" (Umbral, 1979b: 63, 74).

${ }^{16}$ El subrayado es mío.
} 
Entonces, ¿quién podía ser esta joven rubia, vecina del escritor, hija de un pintor ${ }^{17}$, cuyo nombre empezaba con una «M»? Anna Caballé no se atrevió a llamarla, tampoco desvelar su nombre (Caballé, 2004: 343) ${ }^{18}$.

Entonces, ¿quién podía ser esta joven rubia, vecina del escritor, bija de un pintor ${ }^{19}$, cuyo nombre empezaba con una «M»? Anna Caballé no se atrevió a llamarla, tampoco desvelar su nombre (Caballé, 2004: 343).

Habría que esperar un decenio para poner una cara a aquella «M», hasta que se publique El invitado amargo (Molina-Foix; Cremades, 2014), una novela escrita a cuatro manos por Vicente Molina-Foix y Luis Cremades sobre su historia de (des)amor en los últimos años de la Movida. Molina-Foix es poeta, autor dramático, novelista, crítico y director de cine homosexual; solo tuvo dos relaciones sentimentales con mujeres y vive ahora con su novio de manera abierta ${ }^{20}$.

En las primeras páginas firmadas por Molina-Foix aparece la inicial «M»:

M. era la hija de un formidable muralista republicano, exiliado largo tiempo en Latinoamérica y pintor allí al servicio del dictador Trujillo, a la que yo amaba de un modo inesperado, incierto en su continuidad y por ello quizá más frenético. Nos habíamos conocido seis meses antes, al principio del verano de 1978, ella saliendo de una historia de amor con un hombre casado de gran renombre que le doblaba en años ${ }^{21}$.

¿Sería esta famosa «M» la hija del pintor mencionado por María España, la jovencita que inspiró Los amores diurnos, la que puso su matrimonio en peligro? Es un hecho conocido que Umbral se relacionaba con pintores y conocía bien el mundo de las galerías.

La investigación tomaba un nuevo rumbo y tras horas y horas repasando artículos umbralianos dedicados al mundo de la pintura, por los que desfilaban Pepe Díaz y Álvaro

\footnotetext{
${ }^{17}$ El subrayado es mío.

18 «Me cuesta reaccionar, porque en unos pocos minutos el plomo de la conversación me ha hecho evidente la dificultad del trabajo, y por primera vez dudo tanto de su utilidad que decido tomarme unas semanas para pensar. ¿Es que tengo derecho a llamar a la mujer que inspiró 'Los amores diurnos' o a cualquiera de las que han tenido una relación con Umbral, invitándolas a revivir una experiencia que finalmente ha resultado negativa para ellas y que prefieren olvidar?» (Caballé, 2004: 343).

${ }^{19}$ El subrayado es mío.

20 «Molina Foix es abiertamente gay y ha tratado la temática homosexual en muchos de sus libros, especialmente en su novela "La comunión de los atletas", en "Los ladrones de niños" y en "El invitado amargo" (2014)». Diputación de Zaragoza, servicio de Archivos y Bibliotecas, 2019. Vicente Molina Foix estará esta semana en Pina, Zaragoza y Borja dentro del ciclo de la DPZ «Conversaciones con el autor», en http://www.dpz.es/noticias/vicentemolina-foix-estara-esta-semana-en-pina-zaragoza-y-borja-dentro-del-ciclo-de-la-dpz-conversaciones-con-elautor (último acceso: 27/07/2021).

21 (Molina-Foix; Cremades, 2014: 12).
} 
Delgado, Rafael Álvarez Ortega ${ }^{22}$, Manuel Alcorlo ${ }^{23}$, Eduardo Roldán ${ }^{24}$, José Vela-Zanetti con quien tuvo un amigo común, Miguel Delibes ${ }^{25}$, etc., un artículo de El País, «Los marginales», se hizo más explícito con una referencia directa a la hija de este último pintor: «María Vela-Zanetti, hija del gran Vela-Zanetti, me cuenta que su padre está encerrado en Milagros, el pueblo burgalés, pintando doce horas diarias y sin querer ver a nadie. He ahí otro marginal» (Umbral, 1977).

En efecto, José Vela-Zanetti es un pintor y muralista que, a raíz de la Guerra Civil se exilia a una República Dominicana gobernada por Rafael Trujillo. Su hija María nace allí en 1955 y la familia regresa a España en los años sesenta. Entonces, en 1978, María tiene veintitrés años, y Francisco Umbral cuarenta y seis, lo que comprueba las palabras de MolinaFoix: «un hombre casado de gran renombre que le doblaba en años» (Molina-Foix; Cremades, 2014: 12). En cuanto a Molina-Foix, tenía treinta y dos años y da a entender que empezó una historia de amor con Vela-Zanetti cuando compara su edad con la de «sus dos novios anteriores»: «Y allí estaba María, María Vela-Zanetti. [...] Yo tenía al conocerla treinta y dos años y ella veintitrés, una diferencia de edad muy reducida en comparación con la que la separaba de sus dos novios anteriores» (Molina-Foix; Cremades, 2014: 13).

En su novela, Umbral nunca menciona el nombre verdadero de «M». Solo la llama Leticia/Lutecia como para exponer los dos lados distintos que coexisten en una misma persona. Por supuesto, estos nombres no son fortuitos en absoluto. «Leticia» viene del latín, significa felicidad o alegría y remite a la Virgen María, mientras que «Lutecia» se refiere al luto y por consiguiente a la desgracia, al infortunio. Explica al lector que es un personaje de ficción, una persona inexistente, un personaje literaturizado o, mejor dicho, «umbralizado». Esta idea la vuelve a repetir una y otra vez, incluso reiteradamente en la misma página:

\footnotetext{
22 Véase, entre otros: Ateneo de Córdoba (1961): «Umbral, Francisco-Álvarez Ortega pintor de la Adolescencia», en http://www.ateneodecordoba.com/index.php/Rafael_\%C3\%81lvarez_Ortega (último acceso: 24/07/2021).

${ }^{23}$ Véase: «Manuel Alcorlo», en https://elpais.com/diario/1984/04/16/opinion/450914413_850215.html (último acceso: 29/07/2021).

${ }^{24}$ Francisco Umbral y Eduardo Roldán establecen vínculos de amistad y el autor escribe por una parte el prólogo de diversas exposiciones y por otra parte sobre el en varios artículos de El País así como en libros suyos, Trilogía de Madrid o Mortal y rosa. Véase Galería del Rey (2017): «Eduardo Roldán. Ra del Rey, espacio para las artes» en https://www.radelrey.com/roldan (último acceso: 29/07/2021).

${ }^{25}$ De hecho, en su tesis doctoral, Eduardo Martínez Rico nos recuerda que «Umbral completaría su formación extracadémica en la Escuela de Artes y Oficios de Valladolid, donde ingresa en 1946 y aprende a dibujar y a pintar. Permanece en esta escuela local de bellas artes hasta que vio que sus cualidades no le darían para ser un gran pintor. Sin embargo, el gusto por la pintura no le abandonará nunca» (Martínez Rico, 2002: 44).
} 
Llegado a esta altura de mi relato, más allá del millar de páginas, no puedo ni debo mantener más la farsa, sino aclarar lo que el lector ya sabe: que Leticia/Lutecia no existe, sino que es una ficción novelesca de un escritor que no cree en la novela (Umbral, 1979b: 62)

A lo que añade: «Leticia/Lutecia, como todos los personajes de libro, existe y no existe al mismo tiempo, lo cual le ocurre al propio autor y por supuesto al lector, quien, además, paga por existir y no existir como tal lector, pues tiene que comprar el libro del que va a ser el personaje» (Umbral, 1979b: 62).

Se puede interpretar estas palabras de dos maneras: por un lado, uno piensa que Umbral, esbozando aquí un retrato no muy halagüeño de una mujer a la que amó, se da cuenta de que a «M» no le va a gustar para nada verse retratada de tal manera. En efecto, reconoce que «Le va a molestar leer esto a Leticia/Lutecia» (Umbral, 1979b: 134), y entonces se puede deducir que quiere anticipar unas disculpas. Por otro lado, se sabe que el escritor no es ningún cobarde y que ya ha tenido problema con gente que se ha reconocido en sus novelas (véase por ejemplo la polémica que desató la publicación de El Giocondo). Por lo tanto, la reflexión que lleva en Los amores diurnos se tiene que entender como una reflexión literaria sobre la relación entre el autor, sus personajes y sus lectores.

Es más, en su blog literario, «El Boomerang», Vicente Molina-Foix tiene escrito un artículo anterior titulado «La vida privada de María» a raíz del libro Maneras de no hacer nada que ella publicó en 2009. En este artículo, oda a la escritora, el autor precisa las circunstancias de su encuentro. Explica que se conocieron «todos en Madrid a mitad de los años 1970, aunque María Vela-Zanetti era entonces la más joven de un grupo de "literati” usuarios nocturnos del pub Dickens, al que iba, decía, de mera oyente». El pub Dickens era el lugar donde se reunían para unas tertulias literarias con Benet, Savater, Gil de Biedma etc. Y, por supuesto, Francisco Umbral también estaba allí, en el barrio de Salamanca, como lo recuerda Luis de Villena (2017: 59), aunque el establecimiento perdió sus ilustres clientes a lo largo de los años. Asimismo, en su libro Avión Club: Una novela de los ochenta el periodista Carlos Santos los menciona cuando recuerda este lugar «en General Pardiñas. Estaba enfrente del diario Madrid. Pero, en fin, se podría escribir un libro solo con los poetas y los escritores que han pasado por aquí» (Santos, 2017: 294).

En su libro, Molina-Foix narra un episodio inédito y raro que aporta una nueva manera de ver a Francisco Umbral, quizá más ridícula, pero también más humana y tierna: el amante amargo, desilusionado, que llama a su exnovia de noche sin llegar a hablar con ella por teléfono: 
En las noches de aquel verano con María el teléfono empezó a sonar de madrugada. La primera vez estábamos aún despiertos y ella se asustó, como si la llamada, interrumpida al tercer timbrazo, fuese la contraseña de una advertencia. Sonó de nuevo al cabo de unos minutos, y descolgué enseguida preguntando quién era; al otro lado de la línea se oyó un silencio, antes de colgar. Las llamadas se hicieron regulares, aunque espaciadas; los fines de semana no había, y María sabía por qué (Molina-Foix; Cremades, 2014: 13).

Francisco Umbral era un hombre casado que vivía en Madrid entre semana, pero volvía con su esposa María España los fines de semana, y por eso mismo no podía llamarla. Además, Molina-Foix da a entender que Vela-Zanetti no había terminado su relación con él, diciendo que «María, que, sin cortar del todo, seguía viendo a Umbral» (Molina-Foix; Cremades, 2014: 44).

En otra parte del libro, Molina-Foix recuerda otro episodio donde Vela-Zanetti se pone furiosa: «Cuando pocos días después volvió a sonar, estando dormidos, María se incorporó indignada en la cama y quiso contestar ella. "El muy psicópata” (Molina-Foix; Cremades, 2014: 43). No podemos sospechar, con Molina-Foix, que un hombre tan ilustre como Francisco Umbral pudiera haber tenido este tipo de comportamiento, pero de nuevo el autor nos quita la duda al añadir que él «no acababa de creer sus sospechas, hasta que en los artículos diarios que publicaba entonces en El País empezaron las alusiones maliciosas, recogidas y ampliadas meses después en el libro que Francisco Umbral publicó con el título de Los amores diurnos» (Molina-Foix; Cremades, 2014: 43).

Más adelante, Molina-Foix insiste en que Vela-Zanetti es la famosa Leticia/Lutecia de Los amores diurnos publicado en 1979, cuando las relaciones entre ella y el famoso escritor/periodista se habían sosegado y la relación con Molina-Foix acabada:

María Vela pasó por el sofoco de verse retratada bajo el nombre de Leticia/Lutecia en un libro publicado en 1979. Acabado nuestro verano idílico y con él las llamadas de acecho de Umbral, y estando yo de regreso en Oxford, María y su ex se habían visto una vez, aún con reproches y desplantes por parte del amante escocido. Unos días más tarde, la llamó al teléfono, como ya se ha dicho, era un modo de liza muy lumbar. [...] Esas llamadas, tras el encuentro, habían sosegado a María, y en la primera carta que me escribió a Inglaterra, el 16 de octubre del 78, dos días antes de mi cumpleaños, transmitía la nueva paz: «Esta tarde llamo Rumbal con vOz entrecortada y espesa. Se produjo una conversación cortés de la que estoy orgullosa. Banal, corta, sin ninguna cuerda más alta que otra. Cuando notó el despego, se despidió deseándome una vida feliz» (Molina-Foix; Cremades, 2014: 269). 
María Vela-Zanetti es la protagonista de Los amores diurnos, no queda duda. En adelante nuevos indicios, hasta entonces insustanciales o difíciles de comprobar, van a aflorar límpidos en ambos libros. Véase por ejemplo la descripción del nuevo novio de María, descripción en la cual Molina-Foix se reconoce; Umbral le imagina con «sus risas hondas de afeminado falso, sus risas agudas de macho feminoide, contando blasfemias y calumnias de todo el mundo, que nadie escuchaba ya, salvo las maravillosas nubes» (Umbral, 1979b: 178). En El invitado amargo, Molina-Foix confiese haberse comprado el libro en secreto y haberse quedado «hechizado por otros pasajes presumiblemente referidos a mí: "sus risas hondas de afeminado falso, sus risas agudas de macho feminoide"» (Molina-Foix; Cremades, 2014: 271).

Otro indicio relevante radica en cómo Francisco Umbral escribe «Mahlen». En Los amores diurnos, el autor pretende no saber cómo se deletrea, «hl» o «lh», y escribe el apellido del compositor de las dos formas:

Malher. Parece que lo que toca o escucha o vuela es Malher. O Mahler. No sé cómo se escribe. No sé lo que es un paralelogramo ni sé cómo se escribe Malher. Voy siendo rico de ignorancias, de olvidos. Es lo que siempre había deseado. Mahler, con la hache delante de la ele, me queda mejor. Esa hache es como una pausa musical dentro de la música del apellido. Malher, con la hache después de la ele, hace que se vea más la hache, que se corporeice, como un arpa de la orquestra que toca a Malher (Umbral, 1981a: 142).

En otro momento relaciona esta anécdota con su amante, cuando escribe que «Leticia/Lutecia está participando en la moda Malher (o Mahler o como raya se escriba), que es rastro musical de la moda de la película» (Umbral, 1981a: 142-143).

Vicente Molina-Foix nos explica que esto se convirtió en una broma entre Umbral y su amante, ya que ella le había corregido al leer una columna suya en El País en la que lo había ortografiado erróneamente:

Ahí no era Sibelius, que debía de sonar demasiado recóndito a oídos umbralianos, sino Mahler el leitmotiv de su sorna, aunque la primera vez que lo sacó en un artículo de El País le llamó Malher. María le recriminó la ortografía. De ahí que en la novela el propio autor haga broma: "Parece que lo que toca o escucha [sic] o vuela es Malher. O Mahler. No sé cómo se escribe" (Umbral, 1981a: 44).

$\mathrm{Al}$ parecer, esta anécdota a propósito de Mahler persigue a María Vela-Zanetti y a su nuevo novio, Vicente Molina-Foix. Umbral nos deja entender que Molina-Foix le regaló un disco del compositor a María. En efecto, hecho que relata varias veces, así como evoca una posible venganza al haber regalado el disco a otra chica: 
Y finalmente Malher/Mahler del que sólo conozco a un mal actor que le puso de moda, por el cine, y me da por el culo, no me gusta, ni creo que a ti te guste (salvo el donante, claro, el hijoputa). [...] "Jódete amor, Leticia, amor, Lutecia, que el bujarrón de Mahler ya es cosa mía". [...] "He regalado Malher, Leticia, he regalado Mahler para vengarme un poco de mí mismo" (Umbral, 1979b: 186).

También Umbral asocia al compositor y los homosexuales cuando forja la metáfora «ángeles homosexuales de Mahler» (Umbral, 1979b: 186).

Si dejamos estos hechos aparte, es cierto que Umbral fue muy discreto en cuanto a la identidad de Leticia/Lutecia. No obstante, cuando se examina a fondo su obra, uno se da cuenta de que está llena de alusiones a Vicente Molina-Foix, lo que él mismo señala con mucho humor y distancia. De hecho, muchas son las menciones a homosexuales en el relato de Los amores diurnos, y casi siempre estas alusiones están asociadas con María Vela-Zanetti. Umbral imagina que:

la niña iba y venía, subía, bajaba, entraba y salía, frecuentaba historiadores centenarios, buhardillas amargas, humoristas de bombín, poetas homosexuales que siempre pintaban a Luis Cernuda entre arrayanes, pensar que la niña almorzaba en restaurantes rojos con dictadores sudamericanos (Umbral, 1979b: 29).

Es obvia la referencia al dictador Trujillo, de tal modo que se puede deducir que los homosexuales aficionados a la poesía de Cernuda son Vicente Molina-Foix y afines. Se sabe que la carrera literaria de Molina-Foix como poeta empieza a sus veinticuatro años, cuando en 1970 se le incluye en la histórica antología Nueve novísimos poetas españoles de José María Castellet. Además, Umbral se refiere a esta «cuadrilla» de nuevo en el texto de Los amores diurnos cuando se da cuenta de que no está presente en el futuro de su amante: «El cielo de Leticia/Lutecia es el cielo nocturno, y por él vuela muy bajo o muy alto con esas alas en bandada de poetas, homosexuales, profesores, amantes y snobs» (Umbral, 1979b: 141). No puede ocultar sus celos ya que menosprecia el talento del nuevo amante de su exnovia:

Noctámbulos, noctívagos, y nocherniegos, los amores lunares de Leticia/Lutecia eran vagas teorías de chicos que habían sacado un libro de versos que parecía traducido de un inglés del XVIII, o que directamente habían traducido a un inglés del XVII y lo paseaban por la noche madrileña, entre cafetería intelectual y drugstore sentimental, con su casaca y sus manos amarillas de muerto, como el amante que se iban a llevar a la cama (Umbral, 1979b: 177). 
Éste es un episodio que Molina-Foix vuelve a mencionar tal cual en El invitado Amargo cuando narra que «Javier [Marias], que tiene más memoria textual que yo y unas primorosas dotes de imitación, llegó a aprenderse nuestro párrafo favorito [...] y lo recitaba poniendo la voz acampanada de Umbral» (Molina-Foix; Cremades, 2014: 277).

Umbral también alude a la carrera de Molina en Inglaterra cuando se burla celosamente de «poetas jóvenes con borracheras en inglés, profesores con toda la suntuosidad del anonimato literario, cuerpos de macho que van pasando, en la novela de los celos, por el cuerpo de Leticia/Lutecia, y dejándole un rastro de semen, moco, enfermedad y versos en su vagina sin fin» (Molina-Foix; Cremades, 2014: 136). En efecto, el poeta trabajó como profesor de literatura española en Oxford y también se graduó en Historia del Arte por la Universidad de Londres. En total, se quedó en Inglaterra unos ocho años.

El discurso de Francisco Umbral al hablar de su relación de (des)amor con María Vela-Zanetti rebosa celos, los celos que un amante rechazado experimenta, con el dolor de ver a su amor yéndose con otro hombre. De este modo, Umbral no teme declarar en múltiples ocasiones que se pone celoso, muy celoso de Leticia/Lutecia/María. María VelaZanetti ya no le corresponde con su amor, de ahí su comentario sobre el «muy psicópata» que la llama a todas horas de la noche:

cuando [yo] andaba ya receloso, más que celoso, mirando todas las porcelanas de su mansarda de cristal, por saber si en vez de porcelana era semen petrificado de un amante anterior, imposible amante anterior al espíritu casi santo de su virginidad devorada a medias, pero posible amante simultáneo y sospechado siempre, por mí y por todos, en cualquier mujer de carne y semen (Umbral, 1979b: 63).

Los celos le invaden, haciendo de la relación un infierno, lo matan y el autor lo sabe: «Y [él] con el beso comprend[e] que, en el fondo, si había querido llevarme con[s]igo la vulva de la niña era, como siempre, por celos» (Umbral, 1979b: 130). Es interesante subrayar que, según Umbral, «[l]os celos escriben su propio libro, aparte del que esté uno escribiendo» (Umbral, 1979b: 136).

Aunque se da cuenta de que está reaccionando de manera totalmente irracional, los celos le hunden tanto que llega a formular fantasías de muerte. Con la muerte del ser querido viene la certeza que nunca más podrá estar con otra persona. La muerte asegura la fidelidad. Leticia/ Lutecia es infiel, Umbral lo atestigua ${ }^{26}$ y matarla impediría la posibilidad de que ella

26 « [...]para mostrarme, como los trofeos de tu infidelidad, y mi dolor» (Umbral, 1979b: 186). 
lo abandonase. Entonces sí, lo confiesa, suena con matar a «la niña», sea con armas blancas (Umbral, 1979b: 77), sea con sus propias manos:

Esto era primero una caricia que eran diez caricias en una, y luego era una agresión y finalmente un crimen y Leticia/Lutecia se apoyaba contra mí, ya como desvanecida, cayéndoseme, mientras mis diez uñas araban una nieve caliente que prorrumpía en sangre y tesoros. Leticia/Lutecia, en fin, era toda ella una invitación al crimen, y comprendí por primera vez lo que no había pensado comprender jamás: el crimen lujurioso, el crimen orgásmico, el crimen como continuación natural de la eyaculación (Umbral, 1979b: 76).

Francisco Umbral, el literato por antonomasia, el genial inventor de neologismos, el mujeriego, se muestra finalmente inmensamente humano al terminar Los amores diurnos con estas palabras que dicen toda su desesperación: «no se te ve por parte alguna [...]. No estás» (Umbral, 1979b: 223).

Esos celos, cualquier persona que haya estado locamente enamorada los puede comprender, así que, curiosamente y en contra de lo esperado, Molina-Foix sí que lo comprende perfectamente. Aunque le molestan bastante sus llamadas nocturnas y las alusiones despreciativas tanto a su homosexualidad como a su supuesta falta de talento, lo comprende. Molina-Foix sabe que el amor, a veces, enloquece y duele. Concluye este episodio con un comentario de buen tono arguyendo que, «entre las andanadas de agravio al grupo de Oxford y los pormenores excrementicios se traslucía, en el frondoso y exclamatorio estilo bramulesco, una enternecedora declaración de amor a esa ingrata Leticia/Lutecia» (Molina-Foix; Cremades, 2014: 271). De hecho, bajo el título del libro El invitado amargo, afloran esos celos que destrozan todo lo bonito de una relación, y encubre la figura del amante abandonado. Cierto es que esta reacción tan fuerte de Francisco Umbral impresiona al joven poeta de manera positiva, dado que:

conf[ésará] que más allá de las piruetas verbales por ambos lados, y del engorro de que el amante despechado llamase regularmente a mi teléfono y colgase para despertarnos antes del amanecer, empecé a tomarle consideración a Umbral, asombrado yo, con algo de secreta envidia, de que alguien de su estatura literaria y su dimensión pública fuese capaz de bramar, y de dolerse, aunque fuese lumbarmente, por amor (Umbral, 1979b: 186) ${ }^{27}$.

\footnotetext{
${ }^{27}$ Los de la banda de Molina-Foix (María Vela-Zanetti, por supuesto, pero también Javier Marías por ejemplo) le aplicaron a Umbral lo que Molina-Foix llama «el tratamiento VIP». La broma sobre los lumbares frágiles del autor dio lugar a un anagrama irónico: «Lumbar». Parece que fue María Vela-Zanetti quien impulsó el juego, aunque, ni Molina-Foix, ni Javier Marías se quedaron atrás. Admite el autor que «ante esa acometida exagerada pero en el fondo divertente, Javier Marías y yo le sacamos - como parte del juego anagramático que en aquellas fechas cultivábamos cual julianríos sin ánimo trascendental- una variante onomástica de su apellido, Bramul, a
} 
La novela/memoria de María Vela-Zanetti ha permitido, por fin, aclarar quién de verdad se oculta tras la máscara de Leticia/Lutecia aunque no olvidemos que el arte debe sublimar la realidad y lo esencial es la obra literaria resultante. Ahora bien, de querer desvelar quién es quién, más vale acertar y dar a César lo que es de César y no confundirse de personas: Blanca Andreu no es María Vela-Zanetti.

Antes de cerrar este artículo, cabe subrayar otro hecho singular que permite distinguir a ambas protagonistas Blanca Andreu/María Vela-Zanetti entre combates diurnos y nocturnos. En efecto, Umbral no sólo asocia cada libro con un momento del día (día/noche) ${ }^{28}$ sino que lo asocia claramente con una chica diferente. A la Mozart de Los ángeles custodios la describe como una aparición nocturna:

Mozart de improviso. Qué aparición en la noche, qué iluminación. Otra vez la melena de Rimbaud, las gafas punk, la camisa prendida en un solo botón y el olor infantil, casi nenuco, que me trastorna», una visión que luego generaliza a todas las jóvenes cuando afirma que «cada muchacha nocturna es una capilla del día (Umbral, 1981a: 97, 179).

En cuanto a la Rimbaud de La bestia rosa, es «nocturna para siempre» (Umbral, 1981b: 58), a diferencia de Leticia/Lutecia quien pertenece al mundo diurno de manera contundente (véase la referencia onomástica a la luz); asimismo el narrador estipula que sus

imaginaciones diurnas, creaciones de mi día que no eran el día, que no eran del día. Catalina de Siena, las muchachas rojas, el arcángel San Gabriel con pestañas postizas, la pubescente, Leticia/Lutecia, incluso y sobre todo, que era la gran oferta adolescente del día invernal y va cayendo ya, con esa terrible madurez cruel que es la juventud, del lado de la noche (Umbral, 1981b: 104).

\footnotetext{
la que la propia María añadió otra, Lumbar, inspirándose en el hecho de que el polígrafo vallisoletano, y él mismo lo contó por escrito más de una vez, antes de ponerse la ropa cada mañana se vestía de momia» (MolinaFoix; Cremades, 2014: 44).

$\mathrm{Al}$ respecto, reconoce Molina-Foix que «cuando no me sentía con fuerzas para el verso jugaba con las palabras, recuperando a solas los divertimentos anagramáticos que habíamos cultivado Javier Marías y yo en el verano de María Vela y alguna vez, en los años siguientes reaparecían si se daba la ocasión. Ya dije que Umbral pasó a ser en nuestro código privado Lumbar y Bramul, doppelgängers duplicados del escritor, y tan apodícticos e inseparables de él como Bouvard y Pécuchet de Flaubert. Pero el juego también lo extendíamos a nosotros mismos, a nuestros amigos y contemporáneos» (Molina-Foix; Cremades, 2014: 281).

${ }^{28}$ Como lo mencioné más arriba, Los ángeles custodios y La bestia rosa son unos diarios aunque rescinden de fechas. Es interesante reparar en que en La bestia rosa el autor menciona fechas, por ejemplo «Lunes, 22» (Umbral, 1981b: 11), las entradas de Los ángeles custodios solamente mencionan noches: «Marzo. Noche del 15 al $16 »$ (Umbral, 1981a: 7). Además, Umbral describe Los ángeles custodios como un «noctuario» en lugar de «diario».
} 
Como bien se sabe, a Umbral le gusta jugar con las palabras y el autor mezcla alegremente lo diurno con lo nocturno, como por ejemplo en «este cuaderno diurno de mi vida nocturna (de lo nocturno del día)» o en «La mujer es animal de cubil, como ya creo haber anotado en esta especie de diario diurno de un amor nocturno (onírico)» (Umbral, 1979b: 38, 169). En La bestia rosa extiende la metáfora, como lo hace a menudo cuando transfiere una idea, un personaje o una frase de un libro a otro:

Y por la noche eres la lámpara de lo diurno. Así como de día me pareces la gestión secreta de la noche a pleno sol, de noche te ilumina el día ya ido, que se ha quedado en ti, y a tu día nocturno acuden pinchotas, lesbianas, poetas malos, amantes, músicos de barrio, orgasmos, gatos indefinidos, violadores, navajeros, ácratas y funcionarios (Umbral, 1981b: 11).

En resumidas cuentas, no existe una única musa de Umbral sino dos, a la vez parecidas y distintas. Blanca Andreu es una de ellas, la otra es María Vela-Zanetti, una es rubia y la otra es morena; una es diurna y la otra es nocturna. Finalmente, la rotación incesante día/noche metaforiza la rueda de los «amores y amoríos» de Francisco Umbral hasta cristalizar su relación matrimonial en Carta a mi mujer, un libro íntimo y publicado póstumamente. 


\section{BIBLIOGRAFÍA}

Anon (2021): «Poetas del alma», en https://www.poemas-del-alma.com/blancaandreu.htm\#block-bio (último acceso: 23/08/2021).

Ateneo de Córdoba (1961): «Umbral, Francisco-Álvarez Ortega pintor de la Adolescencia», en http://www.ateneodecordoba.com/index.php/Rafael_\%C3\%81lvarez_Ortega (último acceso: 24/07/2021).

Ateneo de Córdoba (1961): «Umbral, Francisco-Álvarez Ortega pintor de la Adolescencia», en http://www.ateneodecordoba.com/index.php/Rafael_\%C3\%81lvarez_Ortega (último acceso: 24/07/2021).

Caballé, Anna (2004): El frío de una vida, Madrid, Espasa.

Castellani, Jean-Pierre (2010): «Paco Pérez Martínez y María España», en Mujeres de Umbral: $77-87$.

Díez, J. Ignacio (2010): «Trío de jóvenes y andróginas», en Mujeres de Umbral : 123-146.

Diputación de Zaragoza, servicio de Archivos y Bibliotecas (2019): «Vicente Molina Foix estará esta semana en Pina, Zaragoza y Borja dentro del ciclo de la DPZ" Conversaciones con el autor"», en http://www.dpz.es/noticias/vicentemolina-foix-estara-esta-semana-en-pina-zaragoza-y-borja-dentro-del-ciclo-de-ladpz-conversaciones-con-el-autor (último acceso: 27/07/2021).

Fundación Antonio Segovia Lobillo (2016): «Rafael Álvarez Ortega-Ateneo de Córdoba», en http://www.ateneodecordoba.com/index.php/Rafael_\%C3\%81lvarez_Ortega (último acceso: 29/07/2021).

Galería del Rey (2017): «Eduardo Roldán. Ra del Rey, espacio para las artes», en https://www.radelrey.com/roldan (último acceso: 29/07/2021).

Martínez Rico, Eduardo (2001): Umbral: vida, obra y pecados: conversaciones, Madrid, Foca.

Martínez Rico, Eduardo (2002): La obra narrativa de Francisco Umbral 1965-2001, Madrid, Tesis para la obtención del grado de Doctor en Filología española bajo la dirección del Prof. Dr. Ignacio Díez, Universidad Complutense de Madrid.

Molina-Foix, Vicente (2009): «La vida privada de María», El Boomeran(g), en: http://www.elboomeran.com/blog-post/79/7219/vicente-molina-foix/la-vidaprivada-de-maria/(último acceso: 10/02/2020).

Molina-Foix, Vicente; Cremades, Luis (2014) El invitado amargo, Barcelona, Anagrama. 
Plaza, José María; Darriba, Manuel; Caballero, Javier (2007): «María España». Crónica, suplemento de El Mundo, en https://www.elmundo.es/suplementos/cronica/2007/619/1188684015.html (último acceso: 03/08/2021).

Santos, Carlos (2017): El avión club, Madrid, La esfera de los libros, en: https://tinyurl.com/2r6k28vb (último acceso: 27/08/2021).

Umbral, Francisco (1977): «Los marginales» en https://elpais.com/diario/1977/05/26/sociedad/233445602_850215.html (último acceso: 10/03/2020).

Umbral, Francisco $\left(1979^{1}\right)$ : Los amores diurnos, Barcelona, Kairós.

Umbral, Francisco (1981'): Los ángeles custodios, Barcelona, Destino.

Umbral, Francisco (1981): La bestia rosa, Barcelona, Tusquets. La sonrisa vertical series, 28.

Umbral, Francisco (1984): «Manuel Alcorlo», en https://elpais.com/diario/1984/04/16/opinion/450914413_850215.html (último acceso: 29/07/2021).

Umbral, Francisco $\left(2008^{1}\right)$ : Carta a mi mujer, Barcelona, Planeta.

Villena, Luis Antonio de (2019¹): Las caídas de Alejandría: los bárbaros y yo, 1997-2018: memorias III. Valencia, Pre-textos. 
SOBRE LA AUTORA

\section{Fabienne Uni}

Contact information: correo electrónico: 